\title{
ANALISA KUALITAS PELAYANAN BIOSKOP TERHADAP KEPUASAN DAN LOYALITAS PELANGGAN MENGGUNAKAN METODE STRUCTURAL EQUATION MODELING (SEM)
}

\author{
Mochammad Edo Herokholiqi, Atikha Sidhi Cahyana \\ Program Studi Teknik Industri \\ Universitas Muhammadiyah Sidoarjo \\ edohero92@gmail.com, atikhasidhi@umsida.ac.id
}

\begin{abstract}
Abstrak
Bioskop XYZ adalah salah satu bioskop di wilayah kabupaten Sidoarjo yang mengutamakan kualitas dan kepuasan konsumen dengan terus memberikan layanan terbaik. Target pasar bioskop XYZ adalah masyarakat dengan ekonomi menengah ke bawah. Karena itu, pemilihan lokasi pendirian bioskop ini ialah pada tingkat kabupaten. Berkembangnya teknologi membuat persaingan bioskop semakin ketat baik dari pesaing, pembajakan film, harapan pelanggan meningkat serta bioskop yang masih dibutuhkan sebagai hiburan alternatif. Maka dari itu pengelola bioskop dituntut untuk lebih kreatif menarik pelanggan dengan berbagai cara antara lain dengan meningkatkan pelayanan. Untuk mengetahui pengaruh kualitas layanan terhadap kepuasan dan loyalitas pelanggan, serta pengaruh kepuasan pelanggan terhadap loyalitas pelanggan agar dapat memberikan beberapa usulan kepada bioskop berdasarkan hasil penelitian. Dalam meneliti hubungan variabel seperti permasalahan di atas digunakan metode Structural Equation Modeling (SEM). Hasil dari penelitian yang mengacu pada hasil uji hipotesa yang dilakukan menunjukkan bahwa variabel kualitas layanan berpengaruh terhadap kepuasan pelanggan, variabel kepuasan pelanggan berpengaruh terhadap loyalitas pelanggan namun variabel kualitas layanan tidak berpengaruh terhadap loyalitas pelanggan. Adapun indikator paling berpengaruh positif kualitas layananan yakni perhatian karyawan, pada kepuasan pelanggan yakni perasaan senang pelanggan dan pada variabel loyalitas pelanggan yakni merekomendasikan pada orang lain.
\end{abstract}

Kata kunci: Bioskop, Kualitas Layanan, Kepuasan Pelanggan, Loyalitas Pelanggan, Structural Equation Modeling

\begin{abstract}
Cinema XYZ is one of cinema in the district of Sidoarjo on the quality and customer satisfaction by continuing to provide the best service. The target market is people with XYZ cinema and lower economic. Therefore, the choice of location of the establishment of this cinema is at the district level. The development of technology to make the competition tighter cinema better than competitors, movie piracy, increased customer expectations and theaters that are still needed as an alternative entertainment. Thus the cinema managers are required to be more creative to attract customers in a variety of ways such as by improving service. To determine the effect of service quality on customer satisfaction and loyalty, as well as the influence of customer satisfaction on customer loyalty in order to give some suggestions to the cinema based on research results. In examining the relationship of variables such as the above issues are used Structural Equation Modeling (SEM). The results of the research which refers to the hypothesis that test results showed that the variables of service quality effect on customer satisfaction, customer satisfaction variables affect the customer loyalty but variable quality of service has no effect on customer loyalty. The indicators most influence positively the quality layananan the attention of employees, customer satisfaction and the customer happy that feeling in the customer loyalty variables recommend to others.
\end{abstract}

Key words: Cinema, Quality of Service, Customer Satisfaction, Customer Loyalty, Structural Equation Modeling 


\section{PENDAHULUAN}

Pada perkembangan zaman saat ini, dapat kita ketahui dalam rutinitas dan kehidupan sering di jumpai masyarakat di daerah perkotaan sangatlah sibuk dengan kehidupan dan aktivitas sehari - hari. Semakin meningkatnya aktivitas masyarakat, maka semakin meningkat pula kebutuhan masyarakat akan hiburan, tempat hiburan yang ada pada perkotaan ada beberapa macam dan bioskop adalah salah satunya.

Semakin berkembangnya teknologi maka persaingan bioskop semakin ketat baik dari pesaing lain maupun pembajakan film yang beredar, mungkin kita semua mengerti begitu cepatnya peredaran film yang baru saja di rilis beberapa hari pada bioskop dan kita bisa mengunduh pada beberapa website dan menyebarkannya dari tindakan pembajakan dengan merekam secara diam - diam pada studio bioskop saat film sedang di putar, sehingga peminat untuk menonton pada bioskop berkurang.

Maka dari itu pengelola bioskop dituntut untuk lebih kreatif menarik pelanggan dengan berbagai cara antara lain dengan meningkatkan pelayanan, memberikan harga tiket murah, makanan dan minuman murah, memberikan bonus ataupun hadiah, adanya jadwal tayang yang di informasikan secara cepat bukan hanya pada media cetak tetapi juga pada media sosial seperti sekarang yang terjadi beberapa bioskop memiliki website, facebook maupun twitter sebagai sarana informasi maupun pemasaran.

\section{LANDASAN TEORI}

\section{A. Kualitas Pelayanan}

Kualitas layanan sangatlah penting untuk dapat di kelola dengan baik oleh sebuah perusahan untuk ditingkatkan melalui perbaikan yang terus menerus agar dapat memuaskan keinginan konsumen. Kualitas pelayanan adalah ukuran seberapa bagus tingkat layanan yang diberikan mampu sesuai dengan ekspektasi pelanggan (Tjiptono dan Chandra dalam Mongkaren, 2013).

Kualitas pelayanan menjadi suatu keharusan yang harus dilakukan perusahaan supaya mampu bertahan dan tetap mendapat kepercayaan pelanggan (Lupiyoadi dalam Mongkaren, 2013).

Jadi sangatlah penting kualitas layanan di kelola dengan cara yang benar agar dapat memberikan pelayanan yang maksimal kepada pelanggan, supaya pelanggan merasa puas dengan layanan yang diberikan karena hal ini berpengaruh pada keberadaan perusahaan jasa dalam dunia industri untuk dapat bersaing dengan pesaing dari perusahaan penyedia jasa yang lain.

\section{B. Kepuasan Pelanggan}

Kepuasan pelanggan akan sangat berdampak baik bagi perusahaan untuk memperoleh keuntungan seperti yang di jelaskan Shin dan Elliot dalam Endarwita (2013) bahwa kepuasan konsumen menciptakan retensi konsumen (consumer retention) yang selanjutnya dapat meningkatkan keuntungan perusahaan, mengingat biaya untuk mempertahankan konsumen yang sudah ada lebih murah daripada biaya mencari konsumen baru.

Hal ini sesuai dengan yang dikatakan Kotler dalam Manoppo (2013), Kepuasan pelanggan adalah tingkat perasaan seseorang setelah membandingkan kinerja (atau hasil) yang ia rasakan di bandingkan dengan harapannya. Kepuasan merupakan tingkat perasaan dimana seseorang menyatakan hasil perbandingan atas kinerja produk jasa yang diterima dan diharapkan ( Kotler dalam Putri dan Nurcaya, 2011).

Kepuasan konsumen atau customer satisfaction adalah sebagai inti dari periode setelah pembelian (Westbrook \& Oliver dalam Sudiarta, 2004). Konsumen akan membandingkan kualitas layanan dengan harapan konsumen sehingga membentuk kepuasan konsumen yang akan berjung kepada loyalitas pelanggan untuk memberikan keuntungan kepada perusahaan dalam jangka panjang. 


\section{Loyalitas Pelanggan}

Loyalitas konsumen merupakan salah satu faktor sukses utama bagi perusahaan untuk memperoleh daya saing yang berkesinambungan (menurut Lee and Cunningham dikutip dari Endarwita 2013), sependapat dengan penyataan tersebut Kloter juga menyatakan dalam Endarwita (2013) bahwa kunci keunggulan bersaing dalam situasi yang penuh persaingan adalah kemampuan perusahaan dalam meningkatkan loyalitas pelanggan.

Loyalitas pelanggan merupakan bagian terpenting pada pengulangan pembelian pada pelanggan (Caruana dalam aryani dan febrina, 2010). Loyalitas adalah suatu kesediaan pelanggan untuk melanjutkan pembelian pada sebuah perusahaan dalam jangka waktu yang panjang dan mempergunakan produk atau pelayanan secara berulang, serta merekomendasikannya kepada teman-teman dan orang lain secara suka rela (Oliver dalam Endarwita, 2013).

Loyalitas pelanggan merupakan salah satu hal yang penting untuk tetap di jaga agar pelanggan tetap setia menggunakan jasa perusahaan, karena loyalitas pelangan merupakan kesetiaan pelanggan untuk menggunakan produk atau jasa dengan melakukan pembelian ulang, seperti yang di sampaikan Oliver dalam Endarwita (2013), menyatakan bahwa loyalitas merupakan suatu komitmen yang kuat yang mendorong untuk terjadinya pembelian kembali.

\section{Metode SEM}

Structural Equation Modeling (SEM) merupakan teknik statistik untuk menguji dan mengestimasi hubungan kausal dengan mengintegrasikan analisa faktor dan analisis jalur (Wright dalam Hartono, 2011).

SEM merupakan suatu teknik analisis multivariat generasi kedua yang menggabungkan antara analisis faktor dan analisis jalur sehingga memungkinkan peneliti untuk menguji dan mengestimasi secara simultan hubungan antara multiple variabel eksogen dan endogen dengan banyak indikator (Gefen dkk, dalam Azizah dkk, 2014).

Aplikasi perangkat lunak SEM sering digunakan untuk membangun model gabungan antara variabel laten dan spesifikasi jalur yang menghubungkan antar variabel. LISREL dan AMOS adalah contoh aplikasi perangkat lunak statistika SEM yang banyak digunakan di bidang sosiologi, manajemen, dan riset sains keperilakuan. LISREL dan AMOS mengestimasi koefisien dari persamaan struktural dan menganalisa model dengan variabel laten diskrit dan kontinu (Kline dalam Hartono, 2011).

\section{METODOLOGI PENELITIAN}

\section{A. Rancangan Penelitian}

Pada penelitian ini digunakan metodologi survei. Metode survei ini bertujuan untuk mendapatkan fakta-fakta dari gejala yang ada dan mencari keterangan secara faktual dari suatu permasalahan yang timbul.

Informasi di dapat dari jawaban-jawaban responden yakni konsumen langsung pengguna jasa pelayanan sebagai objek penelitian dengan memberikan kuesioner yang telah di susun maupun wawancara yang telah di laksanakan.

\section{B. Tahap Penelitian Awal}

Di awali dengan survey awal dilanjut dengan studi literatur yang di dapat dari beberapa jurnal, artikel serta buku dari para ahli. Beberapa teori dasar yang digunakan dalam penelitian ini yakni kualitas layanan, kepuasan pelanggan, loyalitas pelanggan serta metode yang digunakan untuk mengalisa kualitas pelayanan yakni metode SEM (Structural Equation Modelling).

Selanjutnya perumusan masalah kemudian penetapan tujuan penelitian sebagai dasar tujuan dalam menjalankan penelitian sehingga penelitian tersebut sesuai dengan tujuan yang telah di tentukan. Selanjutnya yakni penetapan objek penelitian, tahapan ini dilaksanakan untuk menentukan objek yang digunakan untuk penelitian yakni konsumen yang pernah menjadi pengguna layanan bioskop pada wilayah Sidoarjo yang berumur mulai dari 15 tahun ke atas. 


\section{Identifikasi Variabel}

Pada penelitian ini menggunakan dua variabel, yaitu variabel eksogen atau veriabel independen dan variabel endogen atau varibel dependen, yakni :

1. Variabel eksogen atau variabel independen, yaitu :

a. Kualitas layanan $(\mathrm{X})$

2. Variabel endogen atau variabel dependen, yaitu :

a. Kepuasan konsumen (Y1)

b. Loyalitas pelanggan (Y2)

\section{Konseptual Penelitian}

Hipotesis pada penelitian ini diambil dari penelitian yang dilakukan peneliti lain yakni Terdapat pengaruh yang kuat antara variabel kualitas layanan terhadap kepuasan pelanggan dan tidak terdapat pengaruh antara kualitas layanan terhadap loyalitas pelanggan (Dwi Aryani Dan Febriana R, 2010) serta yang diungkapkan Singh dalam Endarwita (2013) yakni kepuasan merupakan faktor yang berpengaruh langsung terhadap loyalitas konsumen, yakni:

1. H1 : Kualitas pelayanan mempunyai pengaruh terhadap kepuasan pelanggan.

2. $\mathrm{H} 2$ : Kualitas pelayanan mempunyai pengaruh terhadap loyalitas pelanggan.

(Dwi Aryani Dan Febriana R, 2010)

3. H3 : Kepuasan konsumen mempunyai pengaruh terhadap loyalitas pelanggan. (Singh dalam Endarwita, 2013).

\section{HASIL DAN PEMBAHASAN}

\section{A. Gambaran Umum}

Pada penelitian kualitas pelayanan pada biokop XYZ Sidoarjo memliki jumlah responden sebanyak 110 responden untuk mengisi kuisioner yang telah di sebar. Ukuran sampel dalam penelitian ini mengacu bahwa jumlah sampel dapat dihitung dengan besarnya parameter dikali dengan 5 sampai dengan 10, yang telah disebarkan kepada responden yang diharapkan dapat mewakili seluruh populasi mahasiswa yang bekerja. (Hair, dkk, Ferdinand, dan Ghozali dalam Wiyono, 2013).

Pada penelitian ini persentase jenis kelamin 63\% responden adalah berjenis kelamin lakilaki sedangkan untuk perempuan $37 \%$. Pada responden rentang umur jumlah responden yang antara berusia $\geq 15$ tahun mencapai $13 \%$. Untuk rentan usia $\geq 20$ tahun yang paling besar mencapai $57 \%$. Untuk rentan usia $\geq 25$ tahun mencapai $24 \%$, sedangkan pada rentan usia $\geq 30$ dengan jumlah $6 \%$.

Persentase pendidikan dari responden berpendidikan SD yakni $0 \%$, untuk yang berpendidikan SMP yakni 7\% . Sedangkan berpendidikan SMA/K yakni $71 \%$, selanjutnya berpendidikan Universitas dengan persentase $22 \%$.

\section{B. Uji Reliabilitas Dan Validitas}

Data yang akan di uji pada penelitian ini adalah data pendahuluan sebanyak 30 responden dengan menggunakan program SPSS 21. Uji reliabilitas dilakukan untuk mengetahui tingkat konsistensi dari suatu instrumen Jika nilai Cronbach's Alpha yang didapatkan di atas 0,60, maka instrumen yang diuji dapat dikatakan reliabel (Sugiyono dalam Pratiwi dkk, 2012) nilai Corrected item-total correlation di atas 0,3 atau menggunakan $r$ tabel $(0,207)$ maka data tersebut di katakan valid.

Hasilnya bahwa nilai Corrected item-total correlation seluruh indikator pada pengujian data pendahuluan yakni sebanyak 30 responden memiliki nilai di atas 0,3 maupun menggunakan $r$ tabel $(0,207)$ maka keseluruhan indikator adalah valid. Sedangkan nilai Cronbach's Alpha dari keseluruhan variabel memiliki nilai di atas 0,6 maka keseluruhan variabel adalah reliabel. 


\section{Uji Kesesuaian Model}

Model akan di uji kesesuaian model yang bertujuan untuk mengetahui konstruk model sudah fit ataukah belum fit dari setiap variabel maupun keseluruhan model, apabila hasil dari uji kesesuaian adalah model belum fit maka akan dilakukan modifikasi sampai model menjadi fit.

Uji kesesuaian model variabel kualitas layanan pada penelitian, beberapa parameter yang muncul dari uji kesesuaian model antara lain Probability Level, Goodness of fit index (GFI), Adjusted Goodness of Indeks (AGFI), RMSEA, RMR, Comparative fit index (CFI), TuckerLewis Index (TLI), Normo fit index (NFI) menunjukan bahwa parameter RMR dinyatakan fit dengan nilai 0.042 . Hal ini digunakan untuk mengetahui nilai loading factor dari indikator variabel kualitas layanan. Indikator X4 memiliki nilai loading factor tertinggi sebesar 0,690 menunjukkan bahwa indikator tersebut merupakan indikator yang paling berpengaruh pada model kualitas layanan.

Uji kesesuaian model variabel kepuasan pelanggan pada penelitian ini, menunjukan bahwa parameter GFI, RMR, CFI, NFI dinyatakan fit. Indikator Y1.2 memiliki nilai loading factor tertinggi sebesar 0,726 merupakan indikator yang paling berpengaruh pada model kepuasan pelanggan.

Uji kesesuaian model variabel loyalitas pelanggan pada penelitian ini menunjukan bahwa parameter GFI, RMR, CFI, NFI dinyatakan fit. Indikator Y2.1 memiliki nilai loading factor tertinggi sebesar 0,868 merupakan indikator yang paling berpengaruh pada model loyalitas pelanggan.

\section{Struktural Model}

Uji kesesuaian model penelitian ini ditunjukkan pada gambar 4.1 yang telah di proses menggunakan aplikasi uji kesesuaian model yakni AMOS 21.

Hasil dari uji kesesuaian model pada gambar 1 antara lain Probability Level, Goodness of fit index (GFI), Adjusted Goodness of Indeks (AGFI), RMSEA, RMR, Comparative fit index (CFI), Tucker-Lewis Index (TLI), Normo fit index (NFI) bahwa parameter RMR dinyatakan fit dengan nilai di bawah 0.05 yakni nilainya sebesar 0.045 . 


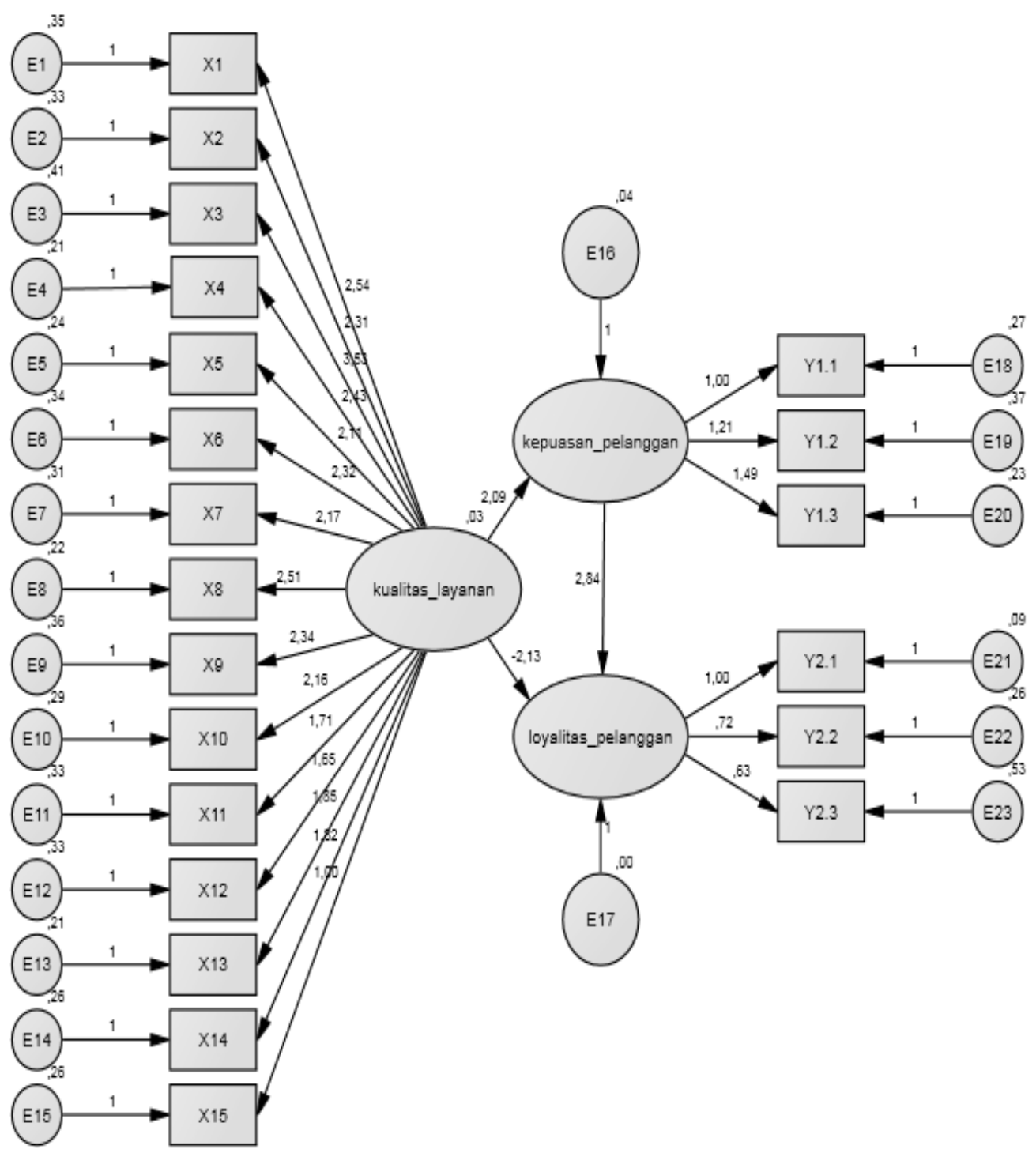

Gambar 1. Model SEM keseluruhan

\section{E. Pengujian Hipotesa}

Berdasarkan pada tabel 1 dapat dilihat hasil dari analisa model pada penelitian ini untuk menguji anatr variabel sesuai dengan hipotesa yang telah di tetapkan pada awal penelitian ini. Dari tabel 1 tersebut dapat di simpulkan bahwa :

1. Kualitas pelayanan mempunyai pengaruh terhadap kepuasan pelanggan.

2. Kualitas pelayanan tidak mempunyai pengaruh terhadap loyalitas pelanggan.

3. Kepuasan konsumen mempunyai pengaruh terhadap loyalitas pelanggan. 
Tabel 1. Hasil uji hipotesa

\begin{tabular}{|c|c|c|c|c|}
\hline Hipotesa & Hubungan & $\begin{array}{c}\text { Standar Cr, } \\
\text { P, T }\end{array}$ & $\begin{array}{l}\text { Hasil } \\
\text { output } \mathrm{Cr} \text {, } \\
\mathrm{P}, \mathrm{T} \\
\end{array}$ & Keterangan \\
\hline \multirow{3}{*}{$\mathrm{H}_{1}$} & \multirow{3}{*}{$\begin{array}{l}\text { Kualitas pelayanan } \\
\text { mempunyai pengaruh } \\
\text { terhadap kepuasan } \\
\text { pelanggan. }\end{array}$} & $\mathrm{Cr}>1,96$ & $\mathrm{Cr}=2,919$ & \multirow{3}{*}{$\begin{array}{c}\mathrm{H} 1, \\
\text { diterima }\end{array}$} \\
\hline & & $P<0,05$ & $\mathrm{P}=0,004$ & \\
\hline & & $\mathrm{T}>0,5$ & $\mathrm{~T}=0,861$ & \\
\hline \multirow{3}{*}{$\mathrm{H}_{2}$} & \multirow{3}{*}{$\begin{array}{l}\text { Kualitas pelayanan } \\
\text { mempunyai pengaruh } \\
\text { terhadap loyalitas } \\
\text { pelanggan. }\end{array}$} & $\mathrm{Cr}>1,96$ & $\mathrm{Cr}=-1,077$ & \multirow{3}{*}{$\mathrm{H} 2$, ditolak } \\
\hline & & $\mathrm{P}<0,05$ & $\mathrm{P}=0,281$ & \\
\hline & & $\mathrm{T}>0,5$ & $\mathrm{~T}=-0,411$ & \\
\hline \multirow{3}{*}{$\mathrm{H}_{3}$} & \multirow{3}{*}{$\begin{array}{c}\text { Kepuasan konsumen } \\
\text { mempunyai pengaruh } \\
\text { terhadap loyalitas } \\
\text { pelanggan. }\end{array}$} & $\mathrm{Cr}>1,96$ & $\mathrm{Cr}=3,18$ & \multirow{3}{*}{$\begin{array}{c}\mathrm{H} 3, \\
\text { diterima }\end{array}$} \\
\hline & & $P<0,05$ & $P=0,001$ & \\
\hline & & $\mathrm{T}>0,5$ & $\mathrm{~T}=1,331$ & \\
\hline
\end{tabular}

Hipotesa 1 Kualitas pelayanan mempunyai pengaruh terhadap kepuasan pelanggan.

Hipotesa pertama sesuai dengan keadaan yang ada bahwa kualitas pelayanan mempunyai pengaruh terhadap kepuasan pelanggan. Pada variabel kepuasan pelanggan indikator Y1.2 (Konsumen merasa senang menonton film di bioskop) memiliki nilai loading factor tertinggi sebesar 0,726 merupakan indikator yang paling berpengaruh pada model kepuasan pelanggan. Sedangkan untuk kualitas layanan yakni indikator X4 (Perhatian karyawan bioskop saat proses pelayanan sudah memuaskan) memiliki nilai loading factor tertinggi sebesar 0,690 merupakan indikator yang paling berpengaruh dan indikator X15 (Karyawan bioskop bersikap ramah dalam proses pelayanan) memiliki nilai loading factor terendah sebesar 0,319 merupakan indikator yang paling tidak berpengaruh pada model kualitas layanan.

Hipotesa 2 Kualitas pelayanan mempunyai pengaruh terhadap loyalitas pelanggan.

Untuk hipotesa yang kedua di tolak karena seluruh parameter yang ada yakni $\mathrm{Cr}>1,96, \mathrm{P}$ $<0,05$ dan $\mathrm{T}>0,5$ tidak memenuhi kriteria yang ada dengan nilai masing-masing nilainya adalah $\mathrm{Cr}=-1,077, \mathrm{P}=0,281$ dan $\mathrm{T}=-0,411$. Dari hasil uji hipotesa dapat di simpulkan bahwa kualitas pelayanan tidak mempunyai pengaruh terhadap loyalitas pelanggan.

Hipotesa 3 Kepuasan konsumen mempunyai pengaruh terhadap loyalitas pelanggan.

Hipotesa sesuai dengan keadaan yang ada bahwa kepuasan konsumen mempunyai pengaruh terhadap loyalitas pelanggan. Pada variabel kepuasan pelanggan indikator Y1.3 (Konsumen percaya terhadap pelayanan Bioskop) memiliki nilai loading factor terendah sebesar 0,661 merupakan indikator yang paling tidak berpengaruh pada model kepuasan pelanggan. Sedangkan untuk loyalitas pelanggan yakni indikator Y2.1 (Memberikan rekomendasi kepada pihak lain untuk menonton film di bioskop) memiliki nilai loading factor tertinggi sebesar 0,868 merupakan indikator yang paling berpengaruh dan indikator Y2.3 (Pelanggan akan menonton film kembali di bioskop) memiliki nilai loading factor terendah sebesar 0,668 merupakan indikator yang paling tidak berpengaruh pada model loyalitas pelanggan.

\section{KESIMPULAN DAN SARAN}

A. Kesimpulan

Beberapa hal yang dapat di simpulkan pada penelitian analisa kualitas pelayanan pada bioskop terhadap kepuasan dan loyalitas pelanggan meggunakan metode sem (structural equation modelling) ini, antar lain:

1. Kualitas layanan mempengaruhi kepuasan pelanggan yang sejalan dengan hipotesa yang dibuat, kualitas layanan tidak mempengaruhi secara langsung variabel loyalitas pelanggan, namun mempengaruhi secara tidak langsung karena kepuasan pelanggan mempengaruhi loyalitas pelanggan. 
2. Indikator perhatian karyawan dalam pelayanan merupakan indikator paling berpengaruh pada variabel kualitas layanan, sedangkan pada variabel kepuasan pelanggan indikator pelanggan merasa senang merupakan indikator yang paling berpengaruh dan indikator rekomendasi kepada orang lain merupakan indikator paling berpengaruh pada variabel loyalitas pelanggan.

\section{B. Saran}

Dari hasil penelitian yang telah dilakukan dan hasil penelitian yang telah di dapat ada beberapa saran yang ditujukan kepada pihak penyedia layanan yakni bioskop Sidoarjo yang berhubungan dengan kualitas layanan terhadap kepuasan pelanggan serta loyalitas pelanggan antara lain :

Hasil penelitian menunjukkan bahwa kualitas layanan sangat mempengaruhi kepuasan pelanggan, dan tingkat perhatian karyawan merupakan indikator yang paling baik pada variabel kualitas layanan. Sedangkan dari variabel kepuasan pelanggan indikator pelanggan merasa senang adalah indikator tertinggi, sehingga dapat di simpulkan bahwa perhatian karyawan mempengaruhi kepuasan pelanggan yakni dapat membuat pelanggan merasa senang.

Kepuasan pelanggan mempengaruhi loyalitas pelanggan, indikator merekomendasikan pada orang lain merupakan indikator yang paling tinggi yang berarti pelanggan akan merasa senang dengan pelayanan bioskop dan akan merekomendasikan pada orang lain.

Diharapkan penyedia layanan bioskop dapat mempertahankan pelayanan yang sudah cukup baik dan segera memperbaiki layanan yang ada seperti yang ada pada indikator kualitas layanan dengan nilai terendah yakni sikap ramah karyawan dalam memberikan pelayanan.

\section{DAFTAR PUSTAKA}

[1] Aryani, Dwi \& Febrina Rosinta. 2010.Pengaruh Kualitas Layanan terhadap Kepuasan Pelanggan dalam Membentuk Loyalitas Pelanggan. Bisnis \& Birokrasi, Jurnal Ilmu Administrasi dan Organisasi.

[2] Azizah, Nur Tria, dkk. 2014.Usulan Peningkatan Prestasi Akademik Berdasarkan FaktorFaktor yang Mempengaruhinya. Jurnal Online Institut Teknologi Nasional. Institut Teknologi Nasional (Itenas) Bandung.

[3] Endarwita. 2013. Pengaruh Kualitas Produk Dan Kualitas Pelayanan Terhadap Kepuasan Dan Loyalitas Nasabah Tabungan Bank Bri Cabang Simpang Empat. e-Jurnal Apresiasi Ekonomi. Sekolah Tinggi Ilmu Ekonomi (STIE) Yappas Pasaman Barat.

[4] Hartono, Jogiyanto. 2011. Konsep Dan Aplikasi Struktural Equation Modeling Berbasis Varian Dalam Penelitian Bisnis. UPP STIM YKPN. Yogyakarta.

[5] Manopo, Ferninda. 2013. Kualitas Pelayanan, Dan Servicescape Pengaruhnya Terhadap Kepuasan Konsumen Pada Hotel Gran Puri Manado. Jurnal EMBA. Universitas Sam Ratulangi Manado.

[6] Mongkaren, Stefi. 2013. Fasilitas Dan Kualitas Pelayanan Pengaruhnya Terhadap Kepuasan Penguna Jasa Rumah Sakit Advent Manado. Jurnal EMBA. Universitas Sam Ratulangi Manado.

[7] Pratiwi, Daniar. Wahyono, Djoko dan Sampurno. 2013, "Analisis Kepuasan Pasien Farmasi Rawat Jalan Menggunakan Metode Servqual: Studi Di Rumah Sakit Swasta X Jakarta", Jurnal Manajemen dan Pelayanan Farmasi, Vol 3, No 1, Hal 25.

[8] Putri, Kadek Indri NS \& I Nyoman Nurcaya. Pengaruh Dimensi Kualitas Pelayanan Jasa Terhadap Kepuasan Pelanggan D\&I Skin Centre Denpasar. Universitas Udayana (Unud) Bali.

[9] Santoso, Singgih. 2012, Analisis SEM Menggunakan AMOS, PT Elex Media Komputindo, Jakarta.

[10] Sudiarta, I Nyoman. 2007. Penerapan Metode Pengukuran Kualitas Pelayanan. Jurnal Manajemen Pariwisata. 
[11] Widjajanti, Kesi \& Nina Ernawati. 2012. Analisis Pengaruh Kualitas Pelayanan terhadap Kepuasan Pelanggan di Warnet USM. J DINAMIKA SOSBUD. Fakultas Ekonomi Universitas Semarang.

[12] Wiyono, Karsono, dan Dewi, Amina Sukma. 2013, "Analisis Anteseden Orientasi Pasar Dan Pengaruhnya Terhadap Pembelajaran Organisasi Umkm Di Eks Karesidenan Surakarta", Semnas Fekon, Optimisme Ekonomi Indonesia, Hal 3. 